\title{
Joint Vendor Quality Assurance Plan
}

National Cancer Institute

\section{Source}

National Cancer Institute. Joint Vendor Quality Assurance Plan. NCI Thesaurus. Code C115777.

A proposed method to describe the operational techniques and activities undertaken within the quality assurance system to verify the fulfillment of the quality requirements for trial-related activities. 